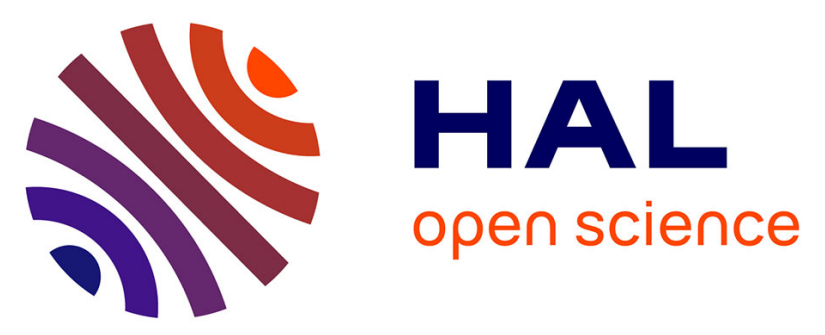

\title{
Primary urinary tract infection: the role of undetected hematogenous seeding of the urinary tract
}

\author{
I. G. Baraboutis, E. P. Tsagalou, J. L. Lepinski, I. Papakonstantinou, V. \\ Papastamopoulos, A. T. Skoutelis, S. Johnson
}

\section{- To cite this version:}

I. G. Baraboutis, E. P. Tsagalou, J. L. Lepinski, I. Papakonstantinou, V. Papastamopoulos, et al.. Primary urinary tract infection: the role of undetected hematogenous seeding of the urinary tract. European Journal of Clinical Microbiology and Infectious Diseases, 2010, 29 (9), pp.1095-1101. 10.1007/s10096-010-0967-2 . hal-00596736

\section{HAL Id: hal-00596736 https://hal.science/hal-00596736}

Submitted on 30 May 2011

HAL is a multi-disciplinary open access archive for the deposit and dissemination of scientific research documents, whether they are published or not. The documents may come from teaching and research institutions in France or abroad, or from public or private research centers.
L'archive ouverte pluridisciplinaire HAL, est destinée au dépôt et à la diffusion de documents scientifiques de niveau recherche, publiés ou non, émanant des établissements d'enseignement et de recherche français ou étrangers, des laboratoires publics ou privés. 
Diseases

Editorial Manager(tm) for European Journal of Clinical Microbiology \& Infectious

Manuscript Draft

Manuscript Number: EJCMID-D-10-00026R1

Title: PRIMARY STAPHYLOCOCCUS AUREUS URINARY TRACT INFECTION : THE ROLE OF UNDETECTED HEMATOGENOUS SEEDING OF THE URINARY TRACT

Article Type: Article

Keywords: Staphylococcus aureus; urinary tract infection; primary staphylococcus aureus urinary tract infection; Escherichia coli urinary tract infection; urinary tract catheterization

Corresponding Author: Dr Ioannis G Baraboutis, M.D.

Corresponding Author's Institution: Evaggelismos General Hospital

First Author: Ioannis G Baraboutis, M.D.

Order of Authors: Ioannis G Baraboutis, M.D.; Eleftheria P Tsagalou, M.D.; Jeanette L Lepinski, R.N.; Ilias Papakonstantinou, M.D.; Vassilios Papastamopoulos, M.D.; Athanasios T Skoutelis, M.D.; Stuart Johnson, M.D.

Abstract: Purpose. Staphylococcus aureus (SA) bacteriuria may accompany SA bacteremia but primary SA urinary tract infection (UTI) may also occur. Our clinical observation of SA UTIs following intravenous catheter-related phlebitis lead us to review hematogenous and ascending route-related risk factors in patients with primary SA UTIs.

Methods. Charts from all patients with SA UTIS over 11/2 year period were reviewed for concurrent or recent hospitalization, intravenous catheterization and for known UTI risk factors. Patients with concurrent SA bacteremia were excluded. Patients with E.coli UTIs during the same period were included as controls.

Results. Twenty cases of primary SA UTI were compared with 43 E.coli UTI cases and did not differ in age, diabetes mellitus, prostatic hypertrophy, previous UTI and other urinary tract (UT) abnormality. However, cases were more likely than controls to have had recent or concurrent hospitalization, UT catheterization and history of recent phlebitis. In multivariate analysis, UT catheterization and recent hospitalization retained significant association with SA UTI. Similar results were shown for the methicillin-resistant SA UTI subgroup.

Conclusions. Even though UT catheterization is the main predisposing factor for primary SA UTI, some cases may be mediated through unrecognized preceding bacteremia related to intravascular device exposure or other healthcare-related factor.

Response to Reviewers: EJCMID - D 10 - 00026

Answers to Reviewers' comments:

Reviewer \#2: This is a retrospective analysis of 20 cases of staph aureus bacteriuria without a concurrent SA bacteremia. The authors conclude that, despite the main predisposing role of UTI 
catheterization, unrecognized transient bacteremia due to recent hospitalization and intravascular device exposure in these patients, may play an important role for SA UTI. The study has some interesting hints and, although retrospective, may give some important messages for this not well defined entity.

However, the information given cannot support a full paper submission, but rather a brief report.

ANSWER. The manuscript is being resubmitted using the "concise article" format, as requested by the Editorial Office.

The authors should clarify the number of patients with upper or lower UTI, as it is interesting to identify whether SA bacteriuris is related to pyelonephritis or not.

ANSWER. We tried to avoid studying just bacteriuria by using quite strict criteria to define "urinary tract infection" (ending up this way with 20 patients only). Those are described in the "materials and methods" section. Besides a positive urinalysis and urine culture, we required at least 4 pertinent symptoms (out of the following: dysuria, frequency, hematuria, fever more than $38 \mathrm{oC}$, suprapubic tenderness, costovertebral area tenderness to percussion) AND documentation in the chart of a clinical impression of urinary tract infection by the responsible physicians. Since 1 . there is significant symptom overlap between cystitis, prostatitis and pyelonephritis and 2. the diagnosis written in the patient charts was, in the majority of cases, just "urinary tract infection" without further specification, we feel we do not have data accurate enough to discriminate between upper and lower UTI in the 2 groups. So, we think that "symptomatic urinary tract infection" is the best description we can come up with (we have made appropriate corrections in the "materials and methods" section). Also, we have put a pertinent comment in the "limitations of the study" section.

We thank the Editorial Office and the reviewers for their time and effort

On behalf of the authors

Ioannis G. Baraboutis 
Electronic Supplementary Material
Click here to download Electronic S

Click here to download Electronic Supplementary Material: SA UTI COVER LETTER REVISED.doc (1) (1) (1) (1) (1) (20) (20) (2) (2) (1) (1) (1) 
PRIMARY STAPHYLOCOCCUS AUREUS URINARY TRACT

INFECTION : THE ROLE OF UNDETECTED HEMATOGENOUS

SEEDING OF THE URINARY TRACT

\section{INTRODUCTION}

Staphylococcus aureus (S. aureus, $S A$ ) is the causative factor of a great variety of infections in outpatients as well as in hospitalized patients. It is considered one of the commonest causes of nosocomial infection in US hospitals and in many European countries [1]. On the other hand, urinary tract infections (UTI) are one of the commonest types of infections encountered in clinical practice, while they constitute the most common type of nosocomial infection in the US [1]. Up to $95 \%$ of nosocomial UTIs may be associated with indwelling urinary catheters [1]. Despite the above, S. aureus has been known for years to be a relatively rare urinary isolate [2]. Older studies, involving outpatients or inpatients or mixed populations, report a percentage of $0.5 \%$ to $6 \%$ of all positive urine cultures $[3,4,5,6]$. Newer reports mention a $13.1 \%$ contibution of $S$. aureus in a bacteremic UTI case-series involving mostly elderly people in a large community hospital [7]. 
The clinical significance of a positive urine culture for SA has been long debated. Traditionally $S$. aureus has been considered to invade the kidney from the hematogenous route, resulting in intrarenal or perinephric abscesses [6,8]. S. aureus bacteriuria may occur in $7 \%$ of patients with $S$. aureus bacteremia and in $13 \%$ of cases of $S$. aureus endocarditis according to an older study [9], although more recent data doubt this association [10].

On the other hand, some investigators of $S$. aureus bacteremia include the urinary tract as the portal of entry, although infrequently [2]. In vitro, $S$. aureus is able to attach to and aggregate onto uroepithelial cells through glycoproteins found in bladder mucin, like GP51, which is significantly increased in the presence of urinary tract infection [11]. This retrograde pattern of S. aureus UTI (or primary SA UTI) has been mostly documented in elderly men with presence of important predisposing factors in the urinary tract. These include presence of indwelling catheters, obstruction or other abnormalities, instrumentation or surgery $[2,4]$. Rates of secondary bacteremia in these groups of patients have been reported to range from $2.3 \%$ to $8.3 \%[2,4,6,12]$.

Even more puzzling and also much less studied is the clinical significance of SA bacteriuria without documented bacteremia before or after the positive S. aureus urine culture date. A study of SA bacteriuria without documented bacteremia from 1997 speculates a transient unidentified 
bacteremic state, at least for some of these patients [13]. The above speculation of a transient bacteremic state leading to $S$. aureus urine colonization or even UTI (which, if existed, would possibly be another candidate for the definition of "primary SA UTI" besides the already known UTI via the ascending route) could potentially apply to some clinical observations we made in our clinical practice.

- Case-report A: Young woman with eosinophilic meningitis and prolonged hospital stay was seen in f/up with a superficial phlebitis at the site of a previous intravenous catheter in her wrist/forearm. The site was not warm or fluctuant and she had no systemic symptoms so she was treated conservatively with warm compresses. The following visit she mentioned symptoms of a UTI so a urinalysis (UA) and a urine culture (UC) were sent and she was started on trimethoprim-sulfamethoxazole empirically. The UC yielded $>10^{5}$ colonies $/ \mathrm{ml}$ of $S$. aureus (pure growth).

- Case report B: 42 year-old patient with advanced AIDS and HIVrelated dementia was hospitalized briefly for mental status changes. During his hospital stay, he received a brief course of intravenous anti-CMV therapy. The hospital course was uneventful, he improved and was discharged home after 8 days. There was no urinary tract (UT) manipulation during his hospital stay or later and there was no history of UTI or UT abnormality. Four weeks later, 
he was evaluated as outpatient. He had no systemic symptoms but reported new-onset urinary frequency, dysuria and suprapubic pain. UA showed significant pyuria and UC revealed pure growth of $>10^{5}$ colonies $/ \mathrm{ml}$ of $S$. aureus.

We hypothesized that the "primary S. aureus UTI" identified in those two patients was blood-borne in origin. In the first case, it could be related to transient bacteremia related to intravenous site thrombophlebitis, while in the second case there was no obvious primary focus but the patient had been recently hospitalized, received intravenous therapy and was significantly immunocompromised. Several reports of increased rates of $S$. aureus bacteremia in the HIV/AIDS population are now available $[14,15]$.

\section{MATERIALS AND METHODS}

To put our hypothesis in perspective we wanted to further evaluate the occurrence of this phenomenon/syndrome, should it exist. Our study was approved by the Institutional Review Board (IRB) of Northwestern University and Lakeside Lakeside Veterans Affairs (VA) Hospital. We used the Infection Control records of the VA hospital for the purposes of our research. We reviewed the infection control line listing of patients with S. aureus infections of the time period between March 2000 and 
September 2001 and we identified patients with positive urine cultures for S. aureus without documented concurrent $S$. aureus bacteremia. Then, we used the computerized medical record system of our hospital to search the charts of those patients for clinical and microbiological data to support the diagnosis of "SA symptomatic UTI without concurrent bacteremia".

The diagnosis of "symptomatic UTI" was present when all the following criteria were present: 1. positive urine culture for S. aureus in pure growth and $>10^{5} \mathrm{CFU} / \mathrm{mL}, 2$. more than 10 white blood cells per highpower field on urinalysis, 3 . positive test for nitrates or leucocyte esterase, 4. at least 4 out of the following 6 symptoms/signs: dysuria, frequency, hematuria, fever more than $38^{\circ} \mathrm{C}$, suprapubic tenderness, costovertebral area tenderness to percussion and 5. diagnosis of urinary tract infection by the responsible physicians. "Concurrent bacteremia" was defined as at least one blood culture positive for $S$. aureus in the 2 weeks preceding or the 72 hours after the first urine culture yielding S. aureus. By using the above-described definitions, we finally came across with a list of 20 patients eligible for further study.

For those 20 patients, we collected demographic and medical history data about pre-existing illnesses (with attention to conditions predisposing to UTI). We recorded data about prior hospitalization within the last six 
months and inpatient or outpatient status when the urine culture (UC) was obtained. Paper chart notes were also reviewed looking for history of recent hospitalization at another facility possibly not recorded on electronic VA chart.

Dates of prior vascular procedures (peripheral line and/or central venous catheter placement) that took place during the last month before the positive UC date were also recorded. Subsequently, we carefully reviewed all the medical and nursing notes up to 1 month prior to the positive UC date looking for any sign of local inflammation at the site of the peripheral or central catheter entry. We included recordings about local redness, swelling, induration and presence of pus.

Additionally, we looked for data on any kind of UT manipulation during the same time-period. Those included placement and presence of Foley catheter up to 48 hours before the positive UC date and also other urologic procedures.

To compare that patient group ("SA group" or "cases") with other primary UTI cases in which retrograde infection is usually the norm, we looked for a control group of $E$. coli UTI cases without concomitant bacteremia. The exclusion of bacteremic E. coli UTI cases may not have been critical as most $E$. coli bacteremias are thought to be secondary to E. coli UTI and much less likely due to other primary foci of infection. 
We reviewed our microbiology laboratory records for E. coli urinary isolates and identified cases of positive UCs for E. coli without documented concurrent bacteremia for the same time period (March 2000 through September 2001). We went through the exact same procedure as for the SA group (review of computerized medical charts to support the diagnosis of " $E$. coli symptomatic UTI without concurrent bacteremia" based on identical definitions to the ones for SA UTI). After eliminating from our list patients not fitting the pre-specified criteria, we created our control group (almost double in number than the SA cases) by selecting every third eligible case from the modified microbiology list. Finally, we went back to computerized and paper medical charts and collected similar data for our control group as for the SA patients.

Statistical analysis. Collected data were entered into a Microsoft Excel spreadsheet and version 13 of SPSS software was used for data processing. We used Student's t-test for independent samples for comparison of continuous variables and Pearson's chi-square test for categorical variables [or Fisher's exact test in cases of low $(<5)$ cell numbers]. Factors of statistical significance on univariate analysis were used for logistic regression analysis [backward stepwise (Wald)]. A p value of 0.05 or less was used for clinical significance. 


\section{RESULTS AND DISCUSSION}

We were finally able to compare 20 cases of $S$. aureus symptomatic UTI with a control group of $43 E$. coli symptomatic UTI cases. Characteristics of the S. aureus group and the E. coli control group are included in table 1.

Cases $(n=20)$ and controls $(n=43)$ were similar in respect to age ( $71.15 \pm 11.6$ vs. $67.9 \pm 13.5$ yrs, mean \pm SD), diabetes mellitus ( $35 \%$ vs. $31 \%$ ), prostatic hypertrophy (50\% vs. $48 \%$ ), previous UTI (25\% vs. $26 \%$ ), and other UT abnormality (15\% vs. $21 \%$ ). However, cases were more likely than controls to have had recent hospitalization (within the last 6 months) and recent urinary catheterization (p values of 0.012 and 0.0001 respectively). Additionally, cases exhibited a trend, as a group, for having had central line placement the month before the positive UC date (p 0.075) and also more likely to have exhibited signs of inflammed peripheral intravenous line within the same time period (p 0.008). In multivariate analysis, recent urinary catheterization and history of admission during the last 6 months for outpatients remained significant predictors of SA UTI (p 0.000 and 0.006 respectively).

We then attempted to compare each of the 2 subgroups of the SA UTI cases (MRSA and MSSA) with the control cases in a similar manner (table 1). 
MRSA cases. Cases of MRSA UTI $(\mathrm{n}=15)$ did not differ from controls in terms of age, diabetes mellitus, prostatic hypertrophy, previous UTI and other UT abnormality (15\% vs. $21 \%)$. Strong differences again arose between MRSA cases and controls when assessed for hospitalization within the last 6 months (p 0.013) and recent urinary catheterization (p 0.000). Additionally, MRSA cases were more likely to have been inpatients on the date of the positive culture collection ( $\mathrm{p} 0.05)$ and to have exhibited signs of inflammed peripheral intravenous line within the last month before the positive culture dates as opposed to E.coli controls (p 0.049). Both differences in recent urinary catheterization and recent hospitalization for outpatients were predictors of MRSA UTI in regression analysis (p 0.001 and 0.027 , respectively). MSSA cases. That small subgroup again did not differ from controls in terms of age, diabetes mellitus, prostatic hypertrophy, previous UTI and other UT abnormality. Also, no significant differences were noted in any parameter which differed in the previous group analyses, possibly due to low numbers, at least in part.

Even though several types of infectious syndromes caused by $S$. aureus are common in clinical practice and adequately well studied, urinary tract involvement by this pathogen is probably not one of them. The presence of $S$. aureus in urine cultures is not always easy either to explain or to appreciate its significance in order to evaluate and treat accordingly. The 
long-standing concept of SA bacteriuria as a common reflection of SA bacteremia has been cast doubt, even for patients without recent indwelling urinary catheter placement, in terms of cost-effectiveness of extensive source investigations [10,13]. The authors of the 1997 report do not think an extensive evaluation for an occult focus of $S$. aureus infection is warranted for patients with SA bacteriuria, although it should be considered with community-acquired SA bacteriuria, pure growth of $>10^{8}$ organisms $/ \mathrm{L}$ in culture and absence of urinary tract predisposing conditions (mentioned above)[13].

On the other hand, $S$. aureus seems to be an infrequent but definite colonizer of the urinary tract, especially in people with urinary catheters, and, in a minority of those, a cause of symptomatic urinary tract infection [12]. Although urinary S. aureus may be the source of subsequent staphylococcal bacteremia, the proportion of patients with chronic $S$. aureus bacteriuria who subsequently become bacteremic is unknown [12].

Our 2 clinical cases prompted us to investigate another-probably- piece of the puzzle: the circumstances of development of symptomatic urinary tract infection by S. aureus in the absence of documented bacteremia. Our hypothesis was that these circumstances could involve, besides prior urinary tract manipulation leading to SA colonization, a transient bacteremic state, at least for some of the cases, like Sheth et al speculated 
in 1997. We carefully identified patients with the diagnosis of SA UTI without documented preceding or concomitant bacteremia based on strict predefined criteria and we compared them with a control group of E.coli UTI patients in terms of predisposing factors for ascending SA UTI as well as predisposing factors for preceding SA bacteremia, especially focusing on exposure to healthcare system and recent presence of intravascular devices.

The results of our study were in agreement with other reports that urinary catheterization is probably the strongest predisposing factor for colonization and/or infection of the UT by $S$. aureus. Besides that, it did bring up-in our opinion- some interesting hints that other factors related to exposure to the healthcare system may be participating in the process, possibly through transient unrecognized bacteremia, at least in some instances. The SA group had higher rates of recent hospitalization, recent central venous catheter placement and recent line-related peripheral thrombophlebitis. The noticed trend was largely driven by the MRSA patients. There were significantly more inpatients included in the MRSA subgroup than in the control group and they did have higher rates of intravascular device placement preceding the UTI by S. aureus. Additionally, recent hospitalization maintained its significant difference in multivariate analysis between that subgroup and the E.coli control 
group, the latter not without significant exposure to both UT

manipulations and the healthcare system.

Transient, sometimes asymptomatic and spontaneously resolving $S$.

aureus bacteremia, is a well known phenomenon.to experienced clinicians but not adequately studied. Any attempt to further study that phenomenon in a prospective way would be probably unethical, especially when thinking of how devastating $S$. aureus bloodstream infection can be to the point that even the finding of colonization of a removed intravascular catheter without documented bacteremia may warrant immediate antistaphylococcal therapy [16]. Nevertheless, some studies have touched on that issue from different angles. In an older prospective study of sources and outcome of MRSA bacteremia and septicaemia (total of 82 episodes), circulation access sites were the commonest source of the bacteremia with non-surgical wounds including burns, varicose ulcers and bed sores as the next most common [17]. The authors categorized 15 of those episodes of bacteremia as transient and, even though they did not provide exact details, they mentioned that 14 of the 82 episodes resolved without antimicrobial therapy. Patients with transient bacteremia were relatively younger than patients with septicaemia. The 2 groups had, although, similar rates of serious underlying diseases and recent surgery. In $10 \%$ of cases, there was no obvious source for bacteremia. In 3 of those, there had been recent 
surgery, while in 4 of the remaining 5 , patients had been recently receiving intravenous fluids. Staphylococcus aureus can be an infrequent cause of transient bacteremia after tooth surgery [18] and also after both upper and lower gastrointestinal endoscopy, where it has been long realized that bacteremia is usually transient and asymptomatic [19]. Interestingly, the small MSSA UTI group seemed also to have had its share of healthcare and intravascular device exposure despite no detected difference in inpatient status on the culture date. Also, no difference arose in urinary catheterization rates when compared with the E.coli group. More definite conclusions about that group were precluded by its small size.

Strengths of the study. We have not found any prior studies addressing this specific question. We tried our best to apply strict criteria for patient enrollment in the study. The study group derived from a significantly homogeneous population in terms of demographics and underlying illnesses. A significant degree of homogeneity also holds true about completeness of medical care data for the population, based on the almost exclusive care at the VA hospital, computerized medical records and full availability of nursing records. Additionally, we carefully created a control group of E.coli UTI cases based on the same criteria for more accurate comparison purposes. Finally, although we can only speculate that our hypothesis may be true under certain circumstances and in 
certain patients, we believe in our results since they seem to be making physiologic sense in terms of what is known about epidemiology and clinical behavior of $S$. aureus.

Limitations of the study. There was obviously no definite conclusion of a new pathogenetic pathway for $S$. aureus symptomatic urinary tract infection from our retrospective study. Despite our efforts for completeness, we definitely had missing data about hospitalization events, urinary tract instrumentation and and intravascular device use. Still, we believe that if data were even more complete, that would have augmented possible differences between the study groups. In the same line, we did not assess other risk factors for S. aureus bacteremia (surgery etc). Additionally, since a. there is significant symptom overlap between cystitis, prostatitis and pyelonephritis and $\mathrm{b}$. the diagnosis documented in the patient charts was, in the majority of cases, just "urinary tract infection" without further specification, our data were not accurate enough to discriminate between upper and lower UTI in the 2 groups. That is why we maintained the general term "symptomatic urinary tract infection" throughout. Furthermore, we did not obtain outcome data of our study patients. A recent well-designed study reported worse outcomes in those cases of S. aureus bacteremia accompanied by bacteriuria [20]. Finally, patient numbers were small, especially that of the MSSA UTI subgroup. 
We conclude that even though urinary tract catheterization is probably the strongest predisposing factor for primary S. aureus UTI, some cases may be mediated through another pathogenetic mechanism, i.e., unrecognized preceding bacteremia related to intravascular device exposure or other healthcare-related factor. We are not sure if a larger, prospective study could clarify this issue. Still, we believe that clinicians treating patients with $S$. aureus UTI should thoroughly inquire both about recent UT instrumentation and recent hospitalization with intravascular device use.

Note: Part of this work was presented as a poster at the 42th annual IDSA meeting, 30 Sep-3 Oct, Boston, MA (paper 533, page 143 of abstract book).

\section{REFERENCES}

1. [No authors listed]: National Nosocomial Infections Surveillance (NNIS) Report; Data summary from January 1992-June 2004, issued Oct 2004. Am J Infect Control 2004 Dec; 32(8): 470-85.

2. Arpi M, Renneberg J: The clinical significance of Staphylococcus aureus bacteriuria. J Urol 1984 Oct ; 132(4) : 697-700. 
3. Blazevic DJ, Stemper JE, Matsen JM: Organisms encountered in urine cultures over a 10-year period. Appl Microbiol 1972 Feb; 23(2): 421-2.

4. Demuth PJ, Gerding DN, Crossley K : Staphylococcus aureus bacteriuria. Arch Intern Med 1979 Jan; 139(1): 78-80.

5. Pead L, Crump J, Maskell R: Staphylococci as urinary pathogens. $J$ Clin Path 1977 May; 30(5): 427-31.

6. Jepsen OB, Larsen SO, Dankert J, et al: Urinary-tract infection and bacteremia in hospitalized medical patients- a European multicentre prevalence survey on nosocomial infection. $J$ Hosp Infect 1982 Sep; 3(3): 241-52.

7. Ackermann RJ, Monroe PW: Bacteremic urinary tract infection in older people. J Amer Geriatr Soc 1996 Aug; 44(8): 927-33.

8. Sobel JD, Kaye D: Urinary tract infections (Chapter 66) in: Mandell GL, Bennett JE, Dolin R (editors). Principles and Practice of Infectious Diseases. Vol 1, Sixth Edition, Elsevier Churchill-Livingstone 2005.

9. Lee BK, Crossley K, Gerding DN:The association between Staphylococcus aureus bacteremia and bacteriuria. Am J Med 1987 Aug; 65(2): 303-6.

10.Ekkelenkamp MB, Verhoef J, Bonten MJ: Quantifying the 
relationship between Staphylococcus aureus bacteremia and $S$. aureus bacteriuria: A retrospective analysis in a tertiary care hospital. Clin Infect Dis 2007 Jun 1: 44(11): 1457-9.

11.Shupp Byrne DE, Sedor JF, Soroush M, McCue PA, Mulholland SG : Interaction of bladder glycoprotein GP51 with uropathogenic bacteria. J Urol 2001 Apr; 165(4):1342-6.

12. Muder RR, Brenner C, Rihs JD et al: Isolation of Staphylococcus aureus from the urinary tract: Association of Isolation with symptomatic urinary tract infection and subsequent staphylococcal bacteremia. Clin Infect Dis 2006 Jan 1; 42(1): 4650.

13. Sheth S, DiNubile MJ: Clinical significance of Staphylococcus aureus bacteriuria without concurrent bacteremia. Clin Infect Dis 1997 Jun; 24(6): 1268-9.

14. Senthilkumar A, Kumar S, Sheagren JN: Increased incidence of Staphylococcus aureus bacteremia in hospitalized patients with acquired immunodeficiency syndrome. Clin Infect Dis 2001 Oct: 33(8): 1412-6.

15. Jacobson MA, Gellermann H, Chambers H: SAB and recurrent Staphylococcal infection in patients with acquired immunodeficiency syndrome and AIDS-related complex. Am J Med 1988 Aug; 85(2): 172-6. 
16.Ekkelenkamp MB, van der Bruggen T, van de Vijver DA, Wolfs $\mathrm{TF}$, Bonten MJ : Bacteremic complications of intravascular catheters colonized with Staphylococcus aureus. Clin Infect Dis 2008 Jan 1; 46(1): 114-8.

17.Cafferkey MT, Hone R, Kean CT: Sources and outcome for methicillin-resistant Staphylococcus aureus bacteraemia. J Hosp Infect $1988 \mathrm{Feb}$; 11(2): 136-43.

18. Tomás I, Pereira F, Llucián R, Poveda R, Diz P, Bagán JV. Prevalence of bacteraemia follwing third molar surgery. Oral Dis. 2008 Jan;14(1):89-94.

19. Nelson DB: Infection control during gastrointestinal endoscopy. $J$ Clin Lab Med 2003 Mar; 141(3): 159-67.

20. Huggan PJ, Murdoch DR, Gallagher K, Chambers ST:

Concomitant Staphylococcus aureus bacteriuria is associated with poor clinical outcome in adults with $S$. aureus bacteraemia. J Hosp Inf 2008 Aug; 69(4): 345-9. 
Table 1. Comparison of cases of Staphylococcus aureus Urinary tract Infections (UTIs) with Escherichia coli UTIs (controls) with subgroup analysis for methicillin-resistant and methicillin-sensitive isolates.

\begin{tabular}{|c|c|c|c|c|c|c|c|}
\hline $\begin{array}{l}\text { Characteristics } \\
\text { /microorganism }\end{array}$ & $\begin{array}{l}\text { Escherichia } \\
\operatorname{coli}(n=43)\end{array}$ & $\begin{array}{l}\text { All cases of } \\
\text { Staphylococcus } \\
\text { aureus }(n=20)\end{array}$ & $\mathrm{p} / \mathrm{OR}(95 \% \mathrm{CI})$ & $\begin{array}{l}M R S A \\
(n=15)\end{array}$ & $\begin{array}{l}\mathrm{p} / \mathrm{OR}(95 \% \\
\mathrm{CI})\end{array}$ & $\begin{array}{l}\text { MSSA } \\
(n=5)\end{array}$ & $\begin{array}{l}\mathrm{p} / \mathrm{OR}(95 \% \\
\mathrm{CI})\end{array}$ \\
\hline Age & $67.9 \pm 13.5$ & $71,15 \pm 11,6$ & $0,348 / \mathrm{NA}$ & $73.1 \pm 9.9$ & $0.176 / \mathrm{NA}$ & $65.2 \pm 15.2$ & $0.677 / \mathrm{NA}$ \\
\hline Diabetes mellitus & $14 / 43$ & $7 / 20$ & $\begin{array}{l}0,85 / 1.11(0.36- \\
3.41)\end{array}$ & $5 / 15$ & $\begin{array}{l}1.00 / 1.03(0.29- \\
3.61)\end{array}$ & $2 / 5$ & $\begin{array}{l}1.00 / 1.38(0.21- \\
9.22)\end{array}$ \\
\hline $\begin{array}{l}\text { History of } \\
\text { genitourinary } \\
\text { procedure (more than } \\
6 \text { months ago) } \\
\end{array}$ & $6 / 43$ & $4 / 20$ & $\begin{array}{l}0,71 / 1.54(0.38- \\
6.21)\end{array}$ & $4 / 15$ & $\begin{array}{l}0.262 / 2.24(0.53- \\
9.39)\end{array}$ & $0 / 5$ & $\begin{array}{l}1.00 / 0.88(0.78- \\
0.98)\end{array}$ \\
\hline $\begin{array}{l}\text { Benign prostatic } \\
\text { hypertrophy }\end{array}$ & $20 / 43$ & $10 / 20$ & $\begin{array}{l}0,79 / 1.15(0.38- \\
3.32)\end{array}$ & $9 / 15$ & $\begin{array}{l}0.37 / 1.72(0.52- \\
5.69)\end{array}$ & $1 / 5$ & $\begin{array}{l}0.37 / 0.28(0.03- \\
2.78)\end{array}$ \\
\hline $\begin{array}{l}\text { History of urinary } \\
\text { tract infection }\end{array}$ & $16 / 43$ & $5 / 20$ & $\begin{array}{l}0,67 / 0.77(0.23- \\
2.56)\end{array}$ & $4 / 15$ & $\begin{array}{l}1.00 / 0.84(0.22- \\
3.13)\end{array}$ & $1 / 5$ & $\begin{array}{l}\text { 1.00/0.57(0.06- } \\
5.67)\end{array}$ \\
\hline $\begin{array}{l}\text { Other urinary tract } \\
\text { abnormality }\end{array}$ & $9 / 43$ & $3 / 20$ & $\begin{array}{l}0,73 / 0.67(0.16- \\
2.78)\end{array}$ & $2 / 15$ & $\begin{array}{l}0.71 / 0.58(0.11- \\
3.06)\end{array}$ & $1 / 5$ & $\begin{array}{l}1.00 / 0.94(0.094- \\
9.52)\end{array}$ \\
\hline $\begin{array}{l}\text { Inpatient on culture } \\
\text { date }\end{array}$ & $10 / 43$ & $8 / 20$ & $0,17 / 2.2(0.70-6.88)$ & $8 / 15$ & $\begin{array}{l}0.05 / 3.77(1.09- \\
12.99)\end{array}$ & $0 / 5$ & $\begin{array}{l}0.57 / 0.87(0.77- \\
0.98)\end{array}$ \\
\hline $\begin{array}{l}\text { If outpatient, } \\
\text { admission last } 6 \\
\text { months }\end{array}$ & $4 / 43$ & $8 / 20$ & $\begin{array}{l}0,012 / 6.5(1.66- \\
25.14)\end{array}$ & $6 / 15$ & $\begin{array}{l}0.013 / 6.5(1.51- \\
27.93)\end{array}$ & $2 / 5$ & $\begin{array}{l}0.11 / 6.5(0.82- \\
51.2)\end{array}$ \\
\hline $\begin{array}{l}\text { Inpatient on culture } \\
\text { date or recent } \\
\text { admission } \\
\end{array}$ & $14 / 43$ & $16 / 20$ & $\begin{array}{l}0,000 / 8.28(2.33- \\
29.44)\end{array}$ & $14 / 15$ & $\begin{array}{l}0.000 / 29.0(3.46- \\
243.22)\end{array}$ & $2 / 5$ & $\begin{array}{l}1.00 / 1 . .38(0.20- \\
9.22)\end{array}$ \\
\hline $\begin{array}{l}\text { Presence of } \\
\text { indwelling urinary } \\
\text { catheter more than } 48 \\
\text { hours before culture } \\
\text { date }\end{array}$ & $8 / 43$ & $14 / 20$ & $\begin{array}{l}0,0001 / 10.21(2.99- \\
34.81)\end{array}$ & $13 / 15$ & $\begin{array}{l}0.000 / 28.44(5.3 \\
2-151.84)\end{array}$ & $1 / 5$ & $\begin{array}{l}1.00 / 1.09(0.11- \\
11.52)\end{array}$ \\
\hline $\begin{array}{l}\text { Genitourinary } \\
\text { procedure last } 6 \\
\text { months }\end{array}$ & $5 / 43$ & $2 / 20$ & $\begin{array}{l}1.00 / 0.84(0.15- \\
4.78)\end{array}$ & $2 / 15$ & $\begin{array}{l}1.00 / 1.17(0.20- \\
6.77)\end{array}$ & $0 / 5$ & $\begin{array}{l}1.00 / 0.88(0.79- \\
0.98)\end{array}$ \\
\hline $\begin{array}{l}\text { Any intravenous line } \\
\text { last } 30 \text { days }\end{array}$ & $15 / 43$ & $11 / 20$ & $\begin{array}{l}0,13 / 2.28(0.77- \\
6.72)\end{array}$ & $9 / 15$ & $\begin{array}{l}0.089 / 2.8(0.84- \\
9.37)\end{array}$ & $2 / 5$ & $\begin{array}{l}1.00 / 1.24(0.18- \\
8.28)\end{array}$ \\
\hline $\begin{array}{l}\text { Peripheral } \\
\text { intravenous line last } \\
30 \text { days }\end{array}$ & $15 / 43$ & $7 / 20$ & $\begin{array}{l}0,99 / 1.005(0.33- \\
3.05)\end{array}$ & $6 / 15$ & $\begin{array}{l}0.72 / 1.24(0.37- \\
4.16)\end{array}$ & $1 / 5$ & $\begin{array}{l}0.65 / 0.46(0.05- \\
4.55)\end{array}$ \\
\hline $\begin{array}{l}\text { Central venous } \\
\text { catheter last } 30 \text { days } \\
\text { before positive } \\
\text { culture date }\end{array}$ & $2 / 43$ & $4 / 20$ & $\begin{array}{l}0,075 / 5.12(0.85- \\
30.78)\end{array}$ & $3 / 15$ & $\begin{array}{l}0.10 / 5.12(0.76- \\
34.31)\end{array}$ & $1 / 5$ & $\begin{array}{l}0.28 / 5.12(0.37- \\
69.75)\end{array}$ \\
\hline $\begin{array}{l}\text { Any sign of } \\
\text { intravenous line } \\
\text { inflammation last } 30 \\
\text { days before positive } \\
\text { culture date }\end{array}$ & $1 / 43$ & $4 / 20$ & $\begin{array}{l}0,032 / 10.5(1.09- \\
101.19)\end{array}$ & $3 / 15$ & $\begin{array}{l}0.049 / 10.5(0.99- \\
110.35)\end{array}$ & $1 / 5$ & $\begin{array}{l}0.19 / 10.5(0.54- \\
201.71)\end{array}$ \\
\hline
\end{tabular}

Footnote. MRSA: methicillin-resistant Staphylococcus aureus, MSSA: methicillinsensitive Staphylococcus aureus. OR: odds ratio, CI: confidence intervals, NA: not applicable. 